https://cssr.uitm.edu.my/2018/

5th International Conference on Science and Social Research

Le Meridien Kota Kinabalu Hotel, 5 - 6 December 2018

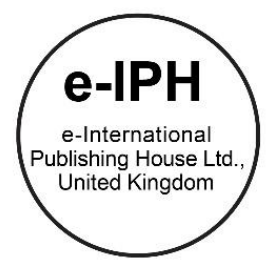

\title{
Towards Implementing Upper Limb Spasticity Simulator(ULSS) in Medical Education; An Integrative Literature Review and Methodology
}

\author{
Nurul Atiqah Othman', Noor Ayuni Che Zakaria1, Fazah Akhtar Hanapiah², \\ Low Cheng Yee ${ }^{3}$, Khairunnisa Johar ${ }^{1}$
}

\author{
1 Faculty of Mechanical Engineering, University Teknologi MARA, 40450 Shah Alam, Selangor Malaysia \\ 2 Faculty of Medicine, Universiti Teknologi MARA, 47000 Sungai Buloh, Selangor Malaysia \\ ${ }^{3}$ Faculty of Mechanical and Manufacturing Engineering, Universiti Tun Hussien Onn, 86400 Parit Raja, Johor Malaysia
}

nurulatiqah_othman@yahoo.com, ayuni.uitm@yahoo.com, fazahakhtar@yahoo.com, low.uth@gmail.com, khairunnisa_johar@yahoo.com

Tel: +6014 3090654

\begin{abstract}
Simulation is widely used in Medical Education as a teaching and learning method. The purpose of this paper is to discover the implication of the simulator into clinical trainee behaviour, medical education, and patient safety. At the other hand, a methodology of quantitative research design towards implementing Upper Limb Spasticity Simulator (ULSS) named BITA1.0 is discussed. The Descriptive Quantitative Research design is focused on formative clinical assessment with students of Master in Rehabilitation, Universiti Teknologi MARA as subjects with pre and postresponse test. With the intention of implementing BITA1.0 into medical education, the result from The Descriptive Quantitative Research is essential.
\end{abstract}

Keywords: simulation; spasticity; upper limb; medical education

eISSN: 2398-42870 2020. The Authors. Published for AMER ABRA cE-Bs by e-International Publishing House, Ltd., UK. This is an open access article under the CC BYNC-ND license (http://creativecommons.org/licenses/by-nc-nd/4.0). Peer-review under responsibility of AMER (Association of Malaysian Environment-Behaviour Researchers), ABRA (Association of Behavioural Researchers on Asians) and cE-Bs (Centre for Environment-Behaviour Studies), Faculty of Architecture, Planning \& Surveying, Universiti Teknologi MARA, Malaysia.

DOI: https://doi.org/10.21834/ebpj.v5iSI3.2552

\subsection{Introduction}

Usage of simulation-based training (SBT) is widely used in medical education to enhance clinical trainee to develop good technical skills (Hammoud et al., 2008, pp. 338-343). Accoding to Gaba (2004), 'Simulation' is referring to imitation to a real problem to achieve an educational goal through experimental learning. The simulator is used worldwide as a teaching and learning method. In medical education, the intervention of simulation was designed to expose clinical trainee into a real clinical scenario without any injury risk to the patients. As a review by Øgård-Repål (2018), limited source to obtain real clinical scenario is the main constraint for the clinical trainee to acquire enough skills and experience (pp. 149-157). Hence, the usage of simulation training with standardized stipulation is giving a big impact to improve the knowledge, performance, confidence level and reduce the anxiety level among clinical trainee (Borg Sapiano et al., 2018, pp 128-133). The purposes of this paper are; to provide an integrative review of the impact of the intervention of simulator in medical education and methodology of quantitative research design in implementing Upper Limb Spasticity Simulator (ULSS) into medical education.

eISSN: 2398-4287C 2020. The Authors. Published for AMER ABRA cE-Bs by e-International Publishing House, Ltd., UK. This is an open access article under the CC BYNC-ND license (http://creativecommons.org/licenses/by-nc-nd/4.0/). Peer-review under responsibility of AMER (Association of Malaysian Environment-Behaviour Researchers), ABRA (Association of Behavioural Researchers on Asians) and cE-Bs (Centre for Environment-Behaviour Studies), Faculty of Architecture, Planning \& Surveying, Universiti Teknologi MARA, Malaysia. DOI: https://doi.org/10.21834/ebpj.v5iSI3.2552 


\subsection{Background of Study}

Several studies have indicated the advantages of applying simulator in medical education. Based on the review, the advantages were divided into three main criteria; Impact on clinical trainee behaviour, Impact on Medical Education, and Impact on Patient Safety.

Table 1. The significant impact of implementing simulator in medical/nursing education.

\begin{tabular}{|c|}
\hline $\begin{array}{l}\text { Experience of lecturers with simulation } \\
\text { training in midwifery education in Slovakia } \\
\text { (Maskálova et al. 2018, pp. 1-3) }\end{array}$ \\
\hline $\begin{array}{l}\text { The effectiveness of virtual simulation in } \\
\text { improving student nurses' knowledge and } \\
\text { performance during patient deterioration: A } \\
\text { pre and post-test design } \\
\text { (Borg Sapiano et al., 2018, pp. 128-133) }\end{array}$ \\
\hline
\end{tabular}

Assessment/method

The intervention of simulator in laboratory practical session for midwifery education. Using low-fidelity simulator when practising normal labour with expert supervision. Subject: Third-year medicine students

To investigate the effectiveness by using virtual simulation in improving nursing student knowledge and performance during patient deterioration. The student is provided a virtual lecture and participated in three scenarios of simulated patient deterioration

Subject: 166 second and third-year diploma and degree nursing student.

Nursing students' perception of high-fidelity To explore the student's perception of using simulation activity instead of clinical simulator into the clinical study course. A placement: A qualitative study (Au et al., 2016, pp. 16-21) qualitative study with the integration of simulator designed for students during clinical lab session.

Subject: 80 years one nursing student.

Clinical simulations for learning medical To measure the effectiveness if using skills: a work-based approach to simulators (Toader, E. 2015, pp. 2443-2448) medical simulation for training and professional assessment. Medicine student attending the clinical simulation course for one semester.

Subject: 135 medicine students.

Simulation Usage in Nursing Fundamentals: A literature study to determine the Integrative Literature Review effectiveness of simulator application in the (Stroup, C. 2014) fundamental nursing study. Analysed 15 research articles out of 193 articles. During the filtering process, from 198 articles, 138 articles were excluded due to title containing exclusionary criteria. Another 43 articles owing to the inclusion of speciality practice areas or upper-level course work, and the last 2 articles were outside the scope of this review.
Patient safety and simulation in prelicensure nursing education: An integrative review (Berndt, J. ,2014, pp 16-22)

An integrative review to analyse the evidence of using the simulator as an education intervention in prelicensure nursing education. The literature study was using Cumulative Index of Nursing and Allied Health Literature (CINAHL), Educational Resources Information Center (ERIC), Medline, and Joanna Briggs Institute (JBI) as a database. There are 17 articles were obtained and classified based on focused on simulation, patient safety, and simulation and patient safety.

Simulation in nursing education: An To evaluate the effectiveness of using evaluation of students' outcomes at their first simulator in reducing anxiety, clinical practice combined with simulations (Khalaila, R., 2014, pp252-258) increasing self-confidence and caring ability among nursing students. Each student scheduled to participate in two simulation days during clinical practice. Subject: 61 second-year nursing students at their first clinical practice.

\section{Analysis Summary}

The engagement of the simulator into midwifery education is beneficial to allow students to practice competencies and skills repeatedly in a safe environment without any risk to patients. The training simulation motivates the student to deal with normal labour case with confidence.

The intervention of simulation is showing an improvement for both knowledge and performance of nursing students during patient deterioration.

The study was found out that the using of the high-fidelity simulator is one of good ways to improve the understanding ability during clinical course study.

Comparing with traditional teaching method, the usage of clinical simulation represents better and comprehensive learning.

Based on the review, the simulator application have positive impacts on students critical thinking development, increasing students and faculty satisfaction level, and the effectiveness in imitating cognitive gains, skills development, and self-confidence ratings

From the study, implementing simulator in a classroom resulting significant improvements in patient safety and more interactive lecture method. Thus, the literature study is supporting the use of the simulator as an educational intervention.

\begin{tabular}{ll}
\hline Evaluation of Simulation in & $\begin{array}{l}\text { The literature research found out } \\
\text { that the intervention of simulator }\end{array}$ \\
Undergraduate Nurse Education: & into nursing education is one of \\
An Integrative Review & effective ways to increase the \\
(Foronda, C., Liu, S., \& Bauman, E. & confidence level and decrease the \\
B. ,2013) & anxiety. Students were satisfied
\end{tabular}


with the teaching and learning

mechanism for clinical education.

Focusing on the first criteria, review from table 1 shows that the intervention of the simulator into the medical education is giving a positive implication towards clinical trainee understanding ability. According to Borg Sapiano et al. (2018), the effectiveness of the virtual simulation was investigated by using pre and post-test design and the findings stated that there are significant improvement of student knowledge and performance after implementing virtual simulation in nursing curricular (pp. 128-133). From the review, it can be concluded that the engagement of the clinical trainee with the simulator is improving the confidence level, critical thinking skill, and reducing the anxiety.

Referring to second criteria, the impact of medical education was written by Mio Leng Au et al. (2016) define that the usage of high-fidelity simulator is giving positive impact on gaining better experience on clinical situation (pp.16-21). As stated by Toader (2015), a Clinical Simulation course is implemented into Medicine student, Faculty of Medicine and the duration of the Clinical Simulation course is one semester (p. 197). After the Clinical Simulation course ended, the practical ability of the students is evaluated by the experts. In term of learning process, it is identify that the teaching and learning process is more comprehensive. With respect to the lecturer view, research by Maskálová et al (2018), stated that the engagement of the simulator during laboratory session for midwifery education is giving a good impact on skills development without risking any lives (pp. 1-3),. The students are allowed to practise repeatedly to understand the environment and labour room needs.

As for the third impact; patient safety, review from Mio Leng Au et al (2016) and Berndt, J. (2014), stated that, with adequate training and skill development, patient safety during real physical engagement is more persuasive serious injury can be avoided (pp. 16-21) \& (pp. 16-22),

Based on the review in Table 1, it can be concluded that the intervention of the simulator into the medical education provides positive intellectual effect, safe practical environment, improving technical skill and develop a better clinical trainee personality.

\subsection{Upper Limb Spasticity Simulator (ULSS)}

Spasticity refers to the abnormal symptom of having resistance in the joints when patients attempt to make a movement (Fujisawa, $\mathrm{T}$, 2007, pp. 48-51). Spasticity can be classified as a syndrome which is known to reduce quality of life (QOL).

Table 2. Summarize of current and previous upper limb simulator projects

High-fidelity Part-task Trainer of Upper
Limb Disorder for Physiotherapist
Education
(Othman, N. A et al., 2018, pp.127-141)
(Che Zakaria, N. A et al., 2015, pp. 31-
36)
(Idris, F, et al.,2017, pp. 328-332)
(Othman, N. A et al., 2016, pp. 731-736
(Othman, N. A, et al., 2015)

(On-Going)

Development of a Haptic Elbow Spasticity Simulator (HESS) for Improving Accuracy and Reliability of Clinical Assessment of Spasticity (Park, H. S et al., 2012, pp. 361-370)
Haptic simulation of Elbow Joint Spasticity

(Grow, D. I et al., 2008, pp. 475-476)

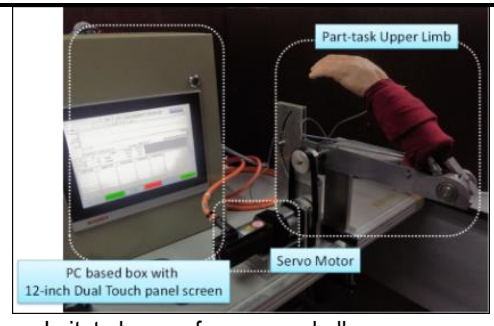

- Imitate human forearm and elbow

- Flexion and extension movements

- Integrated with Programmable Logic Controller (PLC)

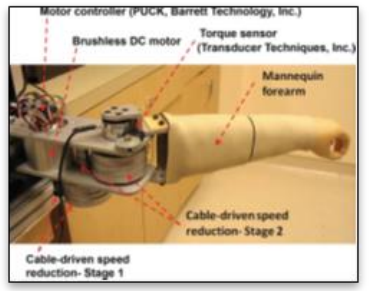

- Imitate human forearm

- Flexion and extension movement with fixed position
The research is focusing on developing an artificial human upper limb for the purposed of medical education. The simulator is able reproduce the stiffness as in patient of upper limb disorder
The haptic simulation has been designed and constructed to recreate the clinical feel of elbow spasticity based on the quantitative measurement. The purpose is for Improving Accuracy and reliability of Clinical Assessment of Spasticity.
The simulator was developed to replicate the spastic arm dynamics for clinical training of physical therapists and neurologists purpose. it is designed as a spastic elbow of a child by using a 


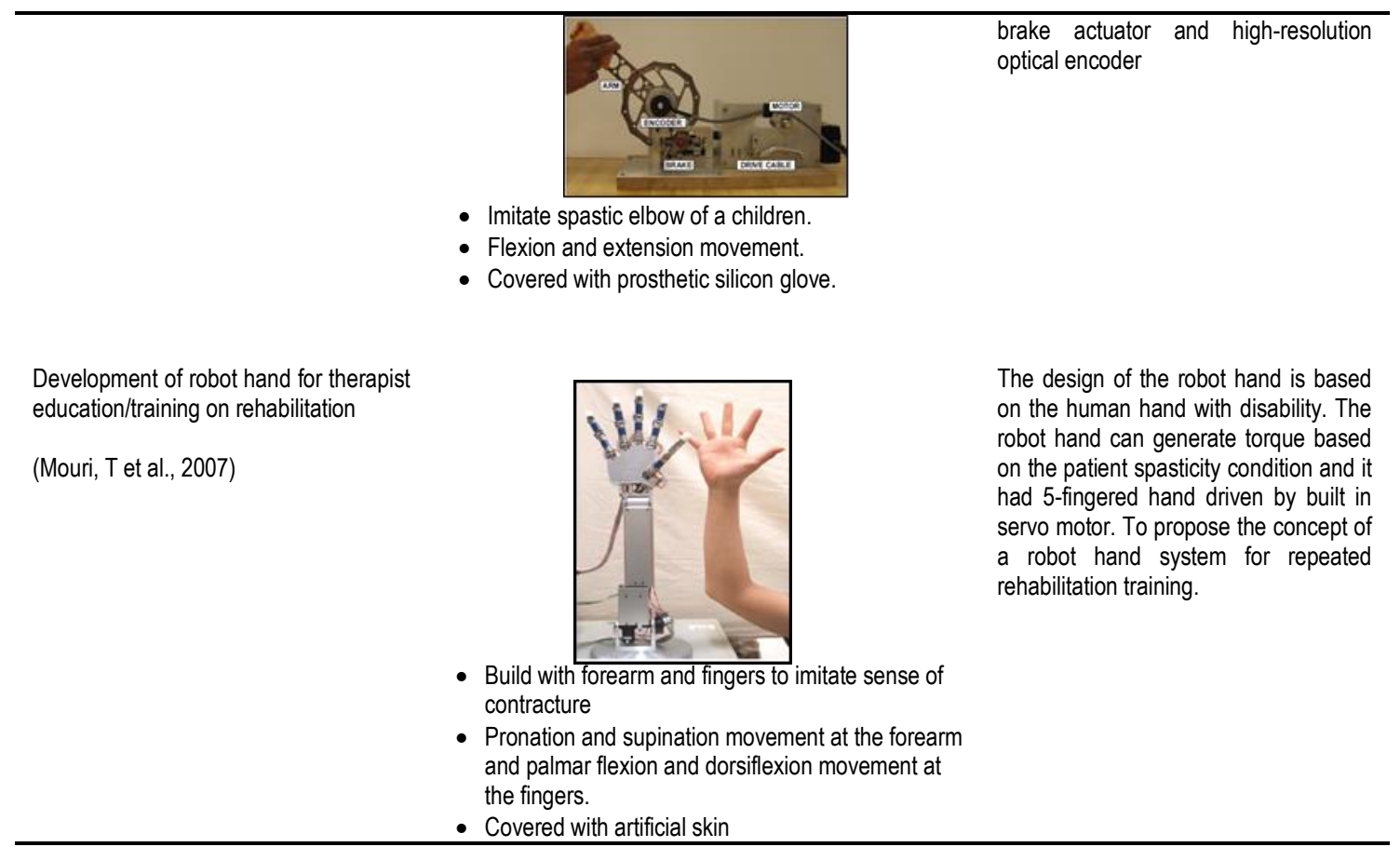

From the literature search, it is shown that the development of part-task trainer for upper limb began in 2008. Previous three projects was developed for rehabilitation training, clinical training of physical therapists and neurologists and research of quantitative measurement respectively. However, the other simulator does not appear to imitate real behaviour of spasticity.

Based on Che Zakaria, N. A (2015) this project began in year 2008 in Shibaura Institute of Technology, Japan with recent collaborative work on further development of the Upper Limb Spasticity Part-task Trainer in Universiti Teknologi MARA (UiTM), Malaysia (pp. 31-36). The Upper Limb Spasticity Part-task Trainer was successfully developed on 2016 and it is named BITA1.0. The targeted end users of the BITA1.0 are students in medical education courses. This particular course is taught with the innovative problem-based learning approach, with an emphasis on practical application of skills and knowledge. With this program, the novice and clinical trainee can also assist the ever-growing demands of public health awareness.

\subsection{Quantitative Research Design; A Methodology}

In an effort to obtain the students perception of intervention of BITA1.0 into medical education, the response from the clinical trainee is crucial to make judgments on the effectiveness of the final prototype. The feedbacks from the students regarding the performance of BITA1.0 in emulating the spasticity symptoms, characteristic and behavior are essential.

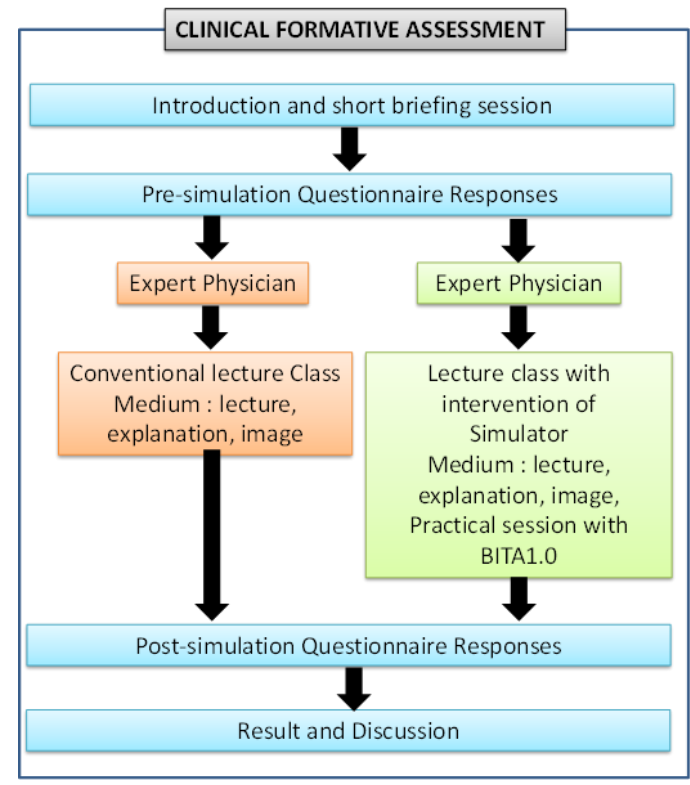

Fig. 1: Design of simulation activity 
Then, the subject is required to attend the lecture class. One group is designed in a conventional lecture class with normal pattern of teaching and learning process. The other group of subject will attend a lecture class and ended with practical session with BITA1.0. At the end of the session, all the subjects are required to complete the post-simulation questionnaire response form. All the responses during class and practical session will be recorded for further analysis purpose.

\subsection{Research Implications}

This study was conducted with a main focus of developing the alternative technique to clinical trainee skills through the benefits of transferring industrial robotics precision into medical and healthcare education. By implementing the simulator into the medical education, the characteristic and behaviour of the patient with spasticity is easy to decipher by the clinical trainee. It ensures patient safety and enables clinical trainee to gain experience and build up their confidence before engaging with real patients. On top of that, it leads to the improvement in educational practices and curriculum, by contrivance the mechanical and robotic sections

\subsection{Conclusion}

Since robots and technologies revolutionize with medical education, BITA1.0 intervention will have a major impact on clinical trainees in developing skills and personality. With the intention of implementing BITA1.0 in conventional lecture classes, it believes the teaching and learning process will be more comprehensive. With better education and research efforts, medical education expectations are far to a higher level.

\section{Acknowledgements}

The authors wish to acknowledge Universiti Teknologi MARA (UiTM) Shah Alam, Selangor for supporting this research under the grant LESTARI [600-IRMI/DANA KCM 5/3/LESTARI (133/2017)].

\section{References}

Hammoud, M. M., Nuthalapaty, F. S., Goepfert, A. R., Casey, P. M., Emmons, S., Espey, E. L., ... Peskin, E. G. (2008). To the point: medical education review of the role of simulators in surgical training. American Journal of Obstetrics and Gynecology, 199(4), 338-343. doi: 10.1016/j.ajog.2008.05.002

Gaba, D. M. (2004, October). The future vision of simulation in health care. Quality and Safety in Health Care. https://doi.org/10.1136/qshc.2004.009878

Øgård-Repål, A., Presno, Å. K. D. \& Fossum, M. (2018). Simulation with standardized patients to prepare undergraduate nursing students for mental health clinical practice: An integrative literature review. Nurse Education Today, 66, 149-157. doi: 10.1016/j.nedt.2018.04.018

Borg Sapiano, A., Sammut, R., \& Trapani, J. (2018). The effectiveness of virtual simulation in improving student nurses' knowledge and performance during patient deterioration: A pre and post test design. Nurse Education Today, 62, 128-133. https://doi.org/10.1016/j.nedt.2017.12.025

Maskálová, E., Urbanová, E., Bašková, M., \& Kvaltínyová, E. (2018). Experience of lecturers with simulation training in midwifery education in Slovakia. Midwifery, 59, 1-3. https://doi.org/10.1016/..midw.2018.01.001

Au, M. L., Lo, M. S., Cheong, W., Wang, S. C., \& Van, I. K. (2016). Nursing students' perception of high-fidelity simulation activity instead of clinical placement: A qualitative study. Nurse Education Today, 39, 16-21. https://doi.org/10.1016/..nedt.2016.01.015

Toader, E. (2015). Clinical Simulations for Learning Medical Skills: A Work-based Approach to Simulators. Procedia - Social and Behavioral Sciences, 197, 24432448. https://doi.org/10.1016/j.sbspro.2015.07.408

Stroup, C. (2014, March). Simulation usage in nursing fundamentals: Integrative literature review. Clinical Simulation in Nursing. https://doi.org/10.1016/j.ecns.2013.10.004

Berndt, J. (2014). Patient safety and simulation in prelicensure nursing education: An integrative review. Teaching and Learning in Nursing, 9(1), 16-22. https://doi.org/10.1016/j.teln.2013.09.001

Khalaila, R. (2014). Simulation in nursing education: An evaluation of students' outcomes at their first clinical practice combined with simulations. Nurse Education Today, 34(2), 252-258. https://doi.org/10.1016/j.nedt.2013.08.015

Foronda, C., Liu, S., \& Bauman, E. B. (2013, October). Evaluation of simulation in undergraduate nurse education: An integrative review. Clinical Simulation in Nursing. https://doi.org/10.1016/j.ecns.2012.11.003

Fujisawa, T., Takagi, M., Takahashi, Y., Inoue, K., Terada, T., Kawakami, Y., \& Komeda, T. (2007). Basic research on the upper limb patient simulator. In 2007 IEEE 10th International Conference on Rehabilitation Robotics, ICORR'07 (pp. 48-51). https://doi.org/10.1109/ICORR.2007.4428405

Brown, P. (1994). Pathophysiology of spasticity. Journal of Neurology, Neurosurgery and Psychiatry. BMJ Publishing Group. https://doi.org/10.1136/jnnp.57.7.773

Othman, N. A., Zakaria, N. A. C., Ramli, M. H. M., Hanapiah, F. A., Jingye, Y., Yee, L. C., \& Takashi, K. (2018). PLC system to optimize training device of upper limb spasticity. Journal of Mechanical Engineering, 15(2), 127-141 
Che Zakaria, N. A., Komeda, T., Low, C. Y., Hanapiah, F. A., Inoue, K., Dumitrescu, R., \& Kuehn, A. (2015). Value-driven design of a high fidelity part task trainer for upper limb disorders. Jurnal Teknologi, 76(4), 31-36. https://doi.org/10.11113/jt.v76.5480

Idris, F., Zakaria, N. A. C., Low, C. Y., Hanapiah, F. A., \& Othman, N. A. (2017). System Integration of an Upper Limb Disorder Part-Task Trainer with PC-based Control. In Procedia Computer Science (Vol. 105, pp. 328-332). Elsevier B.V. https://doi.org/10.1016/j.procs.2017.01.236

Othman, N. A., Idris, F., Zakaria, N. A. C., Hanapiah, F. A., \& Low, C. Y. (2016). Supporting clinical evaluation of upper limb spasticity with quantitative data measurement in accordance to the Modified Ashworth Scale. In IECBES 2016 - IEEE-EMBS Conference on Biomedical Engineering and Sciences (pp. 731-736). Institute of Electrical and Electronics Engineers Inc. https://doi.org/10.1109//ECBES.2016.7843547

Othman, N. A., Zakaria, N. A. C., Low, C. Y., Hanapiah, F. A., Komeda, T., \& Inoue, K. (2015). Towards A Clinically Compliant Upper Limb Part-Task Trainer In Simulated Learning Program. Jurnal Teknologi, 76(4). doi: 10.11113/jt.v76.5488

Park, H. S., Kim, J., \& Damiano, D. L. (2012). Development of a haptic elbow spasticity simulator (HESS) for improving accuracy and reliability of clinical assessment of spasticity. IEEE Transactions on Neural Systems and Rehabilitation Engineering, 20(3), 361-370. https://doi.org/10.1109/TNSRE.2012.2195330.

Grow, D. I., Wu, M., Locastro, M. J., Arora, S. K., Bastian, A. J., \& Okamura, A. M. (2008). Haptic simulation of elbow joint spasticity. In Symposium on Haptics Interfaces for Virtual Environment and Teleoperator Systems 2008 - Proceedings, Haptics (pp. 475-476). https://doi.org/10.1109/HAPTICS.2008.4479997

Mouri, T., Kawasaki, H., Nishimoto, Y., Aoki, T., \& Ishigure, Y. (2007). Development of robot hand for therapist education/training on rehabilitation. 2007 IEEE/RSJ International Conference on Intelligent Robots and Systems. doi: 10.1109/iros.2007.4399377 